\title{
Program Edukasi Joint Protection Technique Pada Aktivitas Ibu Rumah Tangga
}

\author{
Aniek Puspitosari ${ }^{1^{*}}$ \\ Jurusan Okupasi Terapi, Poltekkes Kemenkes Surakarta \\ *Email: aniekpuspitosari@gmail.com
}

\begin{abstract}
Abstrak
Background: Housewives are synonymous with household chores. These activities are carried out regularly, such as washing clothes, cooking, shopping, sweeping floors, washing dishes, cleaning the house. Housewives also carry out regular activities such as mopping, ironing, sweeping the yard, and gardening. Intensive activities and inappropriate positions performed by housewives have the potential to cause musculoskeletal complaints in the upper extremities such as pain or tingling sensation. Efforts that can be made to reduce these complaints are counseling on the application of the Joint Protection Technique (JPT). JPT aims to reduce pain and improve joint function through the use of an ergonomic approach such as changing movement patterns, modifying tasks and the environment. After participating in extension activities, it is hoped that housewives will be able to apply JPT in household activities without musculoskeletal complaints. Methods: Health education was carried out by distributing leaflets via the WhatApps group, lecturing on explaining images printed on leaflets and demonstrating the application of JPT in housekeeping activities. The counseling participants were housewives in $R W 8$, Kebakkalang, Kemiri Village, Kebakkramat District. The counseling activity took place at the house of one of the residents using equipment such as brooms, buckets of water, clothes, grocery bags, irons, and cooking utensils. Results: Counseling activities were carried out during March 2021 with 16 housewives as participants. Counseling activities still pay attention to health protocols, namely maintaining distance and wearing masks. Participants are able to demonstrate directly the application of the JPT principles in the activities of sweeping, washing clothes, shopping for vegetables, ironing, and cooking with real household context and equipment. Conclusion: Domestic work that is carried out by applying the JPT principle can be carried out without reducing the quality of the work, making the work stages simpler and not causing fatigue.
\end{abstract}

Keywords: health education; housewives; joint protection technique

\section{PENDAHULUAN}

Ibu rumah tangga identik dengan pekerjaan rumah tangga yang dilakukan secara rutin, mulai dari bangun tidur (pagi hari) hingga tidur kembali (malam hari). Rutinitas yang dilakukan setiap hari, seperti mencuci pakaian, memasak, belanja, menyapu lantai, mencuci piring, membersihkan rumah, dan mengurus anak apabila mempunyai anak usia balita. Tingginya intensitas aktivitas yang dilakukan ibu rumah tangga secara terus menerus dapat menimbulkan kelelahan fisik dan psikis. Kelelahan fisik ditandai dengan munculnya nyeri di persendian, kelemahan otot, kekakuan persendian, sensasi kesemutan dan rasa terbakar khususnya pada ekstremitas atas.

Aktivitas kerumahtanggaan yang dilakukan oleh ibu rumah tangga 90\% melibatkan persendian pada ekstremitas atas seperti sendi bahu, siku, dan pergelangan tangan secara intensif. Aktivitas intensif yang dilakukan oleh ibu rumah tangga pada ekstremitas tersebut berpotensi menimbulkan keluhan muskuloskeletal. Dengan adanya keluhan tersebut ibu rumah tangga akan merasakan ketidaknyamanan gerak, kemudian membatasi pergerakan pada bagian nyeri ekstremitas atas sehingga luas gerak sendi ke semua arah berkurang. Nyeri dan kaku sendi bertahan lama dapat menghentikan secara permanen fungsional sendi. Kurang dan berlebihan aktivitas fisik dengan gerakan aktif merupakan faktor resiko timbulnya berbagai penyakit pada ibu rumah tangga. Bila 
gerakan pasif lebih dominan dari pada gerakan aktif dapat menyebabkan kekakuan dan gangguan pada otot sendi.

Tuntutan pekerjaan rumah tangga sering kali menjadi beban bagi ibu rumah tangga untuk mempertahankan aktivitas sehari-hari. Mempertahankan aktivitas pergerakan sendi sangat dianjurkan untuk meminimalkan kontraktur dan mengatasi penurunan fungsional sendi akibat keluhan muskuloskeletal yang muncul (OkuliczKozaryn et all, 2018). Beberapa teknik dalam melakukan aktivitas kerumahtanggaan dapat dilakukan untuk mengurangi keluhan musculoskeletal seperti nyeri ataupun kesemutan, salah satu teknik yang dapat dilakukan yaitu Joint protection technique (JPT).

Penerapan JPT merupakan terapi edukasi untuk individu yang mengalami peradangan pada sendi. JPT juga diterapkan dalam menyusun intervensi untuk pasien. JPT merupakan proses mempengaruhi arthiritis dengan cara modifikasi perilaku dan adaptasi lingkungan yang bertujuan untuk mengurangi tekanan (stres) \& nyeri, mengurangi inflamasi dan mempertahankan struktur sendi. Hammond, et al., (2015) mengatakan JPT bertujuan untuk mengurangi rasa sakit, cacat dan meningkatkan fungsi melalui penggunaan pendekatan ergonomis seperti mengubah pola gerakan, modifikasi tugas dan lingkungan, dan penggunaan alat bantu.

Dari hasil survey awal yang dilakukan setelah hamper setahun situasi pandemic covid-19 di bulan Pebruari 2021 di Desa Kemiri 75\% adalah ibu rumah tangga murni dan 25\% memiliki peran ganda. 90\% ibu rumah tangga di Desa Kemiri tidak menggunakan asisten rumah tangga dalam menjalankan aktivitas kerumahtanggannya. Dan beberapa ibu rumah tangga murni yang tidak menggunakan asisten rumah tangga sering mengeluhkan nyeri yang disebabkan aktivitas yang dilakukan terus menerus. Ditambah situasi pandemic covid 19 menyebabkan beban domestic ibu rumah tangga meningkat seperti frekuensi memasak yang lebih sering, cucian pakaian kotor yang lebih banyak, setrika baju yang lebih banyak, menyapu juga lebih sering karena semua anggota keluarga berada di rumah dikarekanan metode kerja dari rumah (work from home) maupun belajar dari rumah (study from home).

Keluhan muskuloskleetal dari ibu rumah tangga yang disampaikan ke petugas kesehatan (Kader) hanya ditangani dengan adanya pemberian obat tanpa adanya pemberian edukasi terkait keluhan tersebut.

\section{TINJAUAN PUSTAKA}

Joint Protection Technique (JPT) merupakan serangkaian aktivitas dengan cara modifikasi perilaku dan adaptasi lingkungan yang bertujuan untuk mengurangi nyeri tekanan (stres) \& nyeri, mengurangi inflamasi serta mempertahankan struktur sendi (Hammond, et al, 2015). Joint Protection Technique (JPT) memiliki beberapa manfaat dalam menjalankan aktiviras kehidupan sehari - hari. Manfaat dari JPT membantu mengurangi nyeri, peradangan dan tekanan pada sendi selama melakukan aktivitas sehari - hari dan membantu mempertahankan integritas struktur sendi dalam jangka panjang. JPT secara konsisten menekankan manfaat fisik dan psikis (Izzeddin, 2018).

Prinsip - prinsip dalam JPT adalah serangkaian teknik yang dapat dimasukkan ke dalam semua kegiatan. Ini akan mengurangi stres pada persendian. Sendi yang telah dilemahkan oleh radang sendi beresiko rusak oleh stres dan ketegangan. Penggunaan sendi yang sakit secara tidak benar dapat menyebabkan gangguan fungsi dan kelainan bentuk. Teknik perlindungan sendi adalah cara melakukan kegiatan sehingga risiko cacat berkurang. (Hammond, et al., 2015) Beberapa prinsip dalam JPT: 
a. Respect for pain and rest and work balance

Tidak memaksakan diri jika merasa lelah saat melakukan aktivitas serta menyegerakan untuk istirahat agar relaks dan nyeri berkurang.

b. Reduction of effort (energy conservation \& work simplification)

Hindari tergesa-gesa, merencanakan dan mengorganisasi aktifitas dengan baik, seperti meminimalisir aktifitas dengan menggunakan postur body mechanic yang benar yaitu saat hendak bangun dari posisi tidur, lalu bagaimana posisi yang nyaman untuk penempatan tungkai yang sakit ketika tidur, serta bagaimana posisi tumpuan yang bener ketika hendak bangun dari posisi duduk ke berdiri, menempatkan benda agar mudah terjangkau dan aman.

c. Avoidance of positions of deformity

Menghindari penggunaan sendi yang sakit/cacat dengan tidak menggunakan sendi khususnya pada sendi yang terasa nyeri ketika digunakan untuk aktivitas.

d. Use of stronger/large joint change positions that do not tend to be stressful to involved joint

Gunakan sendi yang lebih kuat dan stabil sebagai tumpuan saat melakukan aktifitas. Menjaga sendi punggung tetap lurus sesuai anatomi tubuh, menggunakan alat bantu seperti krek, kursi yang memiliki sandaran saat melakukan aktifitas. Ini bertujuan untuk menghindari posisi berdiri sehingga tidak bertumpu pada lutut dan beban pada lutut berkurang.

e. Avoidance of staying in one positions

Hindari posisi yang sama dalam waktu yang lama, pasien disarankan untuk mengubah posisi setiap 20 menit sekali untuk mengulur otot yang tegang akibat kontraksi secara terus menerus untuk mempertahankan posisi.

Pada pelaksanaan aktivitas ibu dalam melakukan rutinitas kerumahtanggaan dapat menerapkan Joint Protection Technique (JPT)

Tabel 1. Pelaksanaan aktivitas ibu dalam melakukan rutinitas kerumahtanggaan

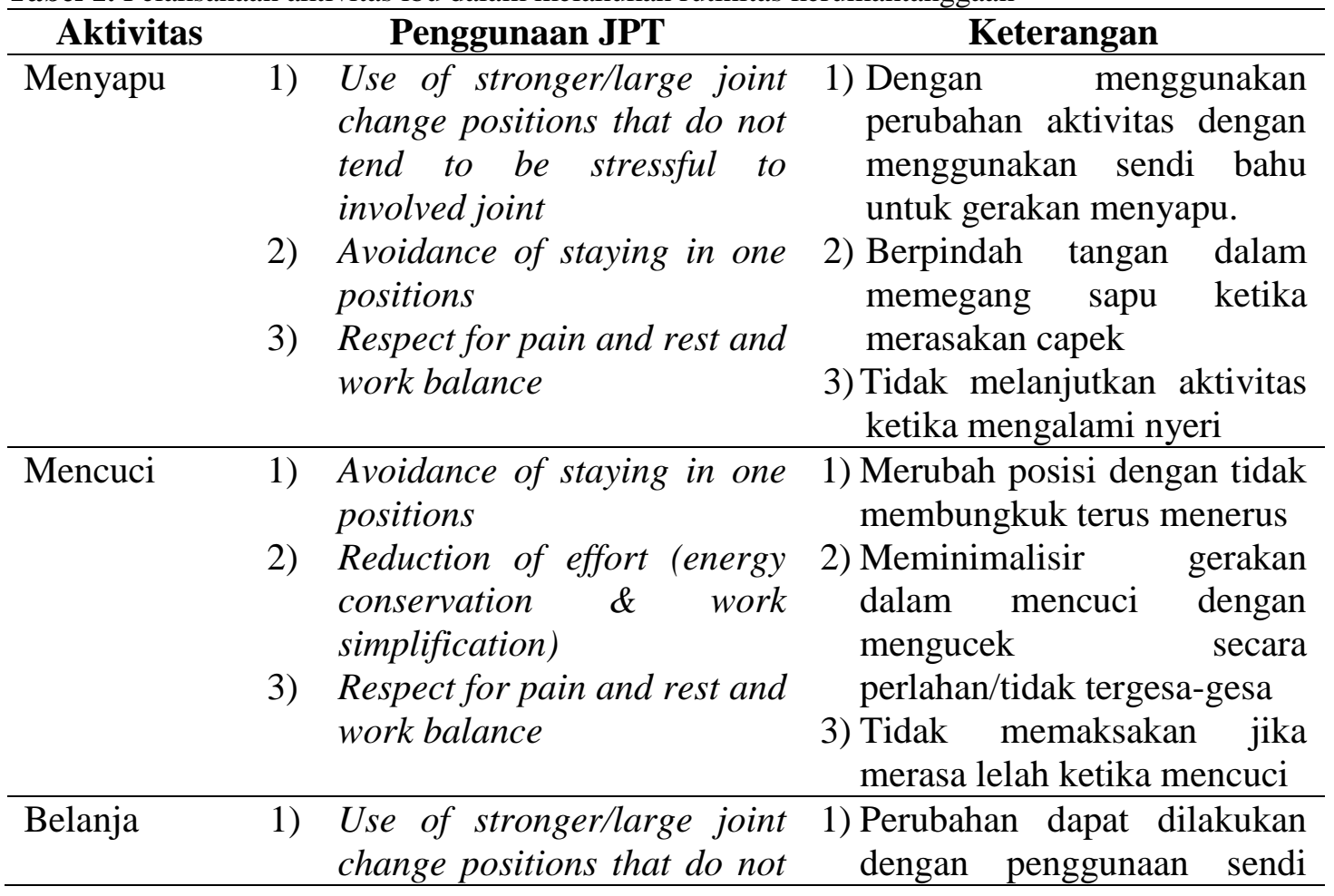




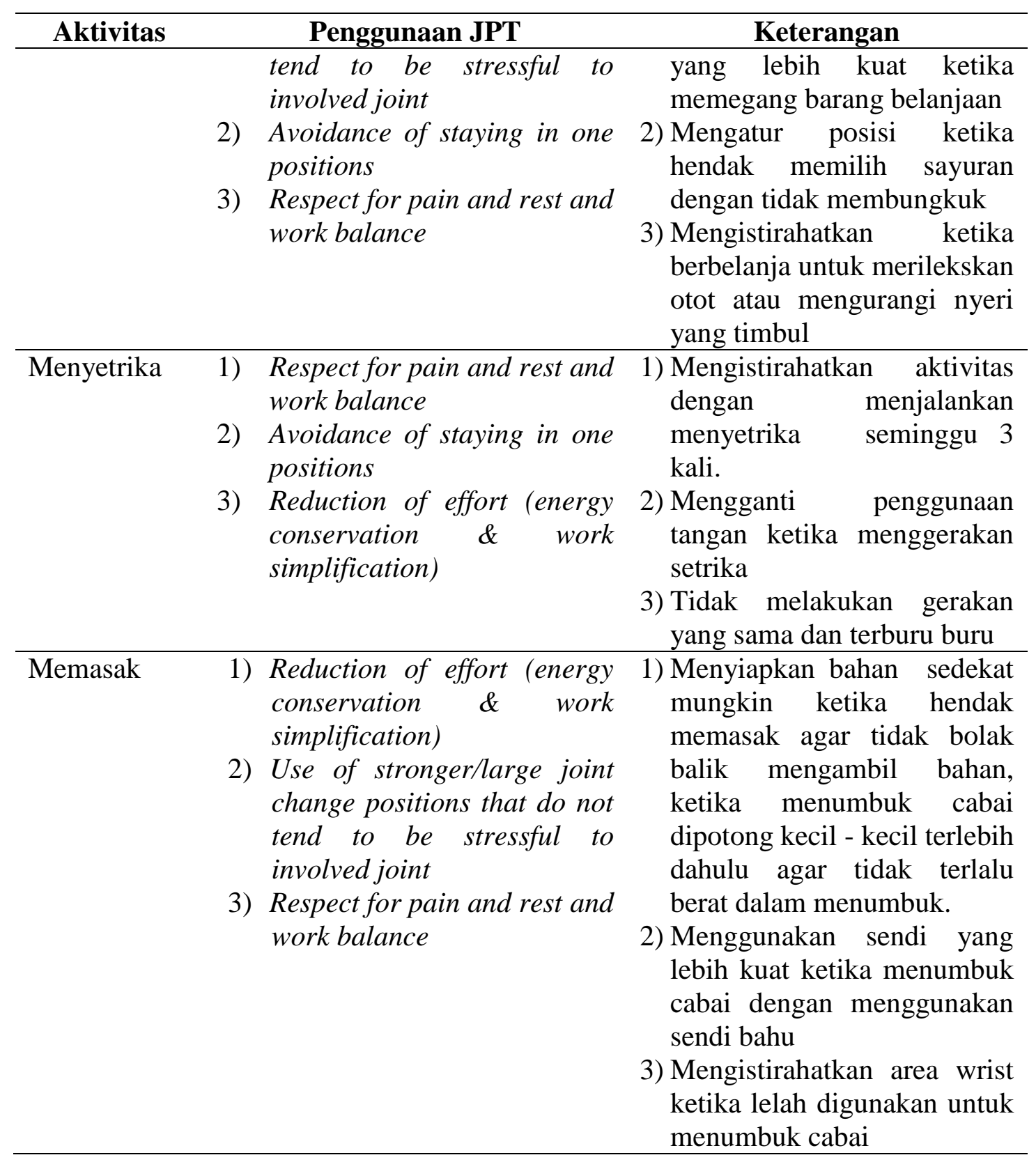

\section{DESAIN PENELITIAN}

Penyuluhan kesehatan dilaksanakan pada hari Sabtu, 13 dan 20 Maret 2021 bertempat di rumah salah satu warga RW 8 Dusun Kebakkalang, Desa Kemiri, Kecamatan Kebakkramat, kabupaten Karanganyar. Peserta kegiatan berjumlah 16 ibu rumah tangga dan tidak memiliki asisten rumah tangga. Peserta datang ketempat penyuluhan dengan menerapkan protokol kesehatan ketat seperti memakai masker, menjaga jarak, membawa hand sanitizer serta beberapa peserta menggunakan face shield.

Dengan menggunakan grup WhattApp, diskusi dimulai pada awal bulan Maret 2021 dan diperoleh hasil bahwa sebagian besar anggota grup mengeluhkan beban domestik kerumahtanggaan yang meningkat selama situasi pandemik covid-19 seperti kondisi rumah yang berantakan, cucian dan setrikaan banyak, kadang memasak 2x dalam sehari. Akibatnya muncul berbagai keluhan fisik seperti nyeri otot, nyeri sendi, 
kesemutan dan merasa cepat lelah serta mudah emosi. Penyuluh memposting instrument Visual Analog Scale (VAS) versi gambar animasi smile dan anggota grup memberikan respon berapa skala nyeri yang dirasakan. Hasil perhitungan rata-rata skala nyeri pada Minggu pertama Maret 2021 adalah skala 4 Pada minggu kedua Maret 2021, penyuluh memposting leaflet yang berisi tentang penerapan prinsip JPT dalam aktivitas kerumahtanggaan.

Minggu ketiga Maret 2021 diadakan pertemuan langsung dengan menerapkan protokol kesehatan. Kegiatan penyuluhan dimulai dengan metode ceramah tentang penerapan JPT dan demontrasi langsung pada aktivitas yang telah tercantum di leaflet yang telah dibagikan di grup WA. Penyuluh mempraktikkan langsung penerapan JPT pada aktivitas menyapu, mencuci baju, berbelanja, menyeterika baju dan memasak. Beberapa peserta ditunjuk untuk mendemontrasikan langsung kegiatan tersebut. Selama 1 minggu kedepan peserta diminta untuk menerapkan prinsip tersebut dalam kegiatannya sehari-hari dan sebagai bukti, peserta diwajibkan mengunggah foto kegiatannya ke grup WA.

Minggu ke empat Maret 2021 diadakan pertemuan kedua untuk berdiskusi tentang manfaat dan apa yang dirasakan peserta penyuluhan setelah seminggu menerapkan prinsip JPT di dalam aktivitasnya. Penyuluh membagikan kembali instrument VAS untuk mengukur skala nyeri peserta. Skala nyeri menunjukkan perubahan, yaitu ratarata skala 2. Kegiatan dilanjutkan dengan penyaluran bantuan sembako kepada peserta.

\section{HASIL PENELITIAN}

Kegiatan yang telah dilaksanakan selama bulan Maret 2021 berjalan dengan baik. Dari segi pelaksanaan, terlihat kesadaran dari peserta telah menerapkan protokol kesehatan dengan memakai masker, menjaga jarak dengan memberi jarak antar kursi, mencuci tangan dengan sabun sebelum masuk ke rumah tempat diselenggarakan pelatihan, memakai hand sanitizer setelah mengisi daftar hadir bahkan beberapa menggunakan face shiled. Dari segi pengetahuan peserta, berdasarkan wawancara maupun tanya jawab yang dilakukan pada sesi kedua penyuluhan, peserta mempunyai pengetahuan yang lebih baik dalam memahai prinsip JPT bahkan ibu rumah tangga tersebut mampu menerapkannya dalam aktivitas lain.

Tidak hanya dalam aktivitas yang yelah dicontohkan pada acara penyuluhan. Ibu rumah tangga mampu menerapkan prinsip JPT ketika beraktivitas lain seperti mengepel, menyapu halaman dengan sapu lidi, menjemur pakaian, menjemur kasur, membersihkan atap rumah dan sebagainya.

\section{PEMBAHASAN}

Joint protection technique (JPT) bertujuan untuk mengurangi stres dan nyeri persendian, mengurangi inflamasi untuk melindungi keutuhan struktur sendi. Dalam kegiatan penyuluhan ini, pelaksana kegiatan mengedukasi Ibu rumah tangga untuk melakukan gerakan yang benar dengan menggunakan prinsip Joint protection technique (JPT) serta ibu rumah tangga dapat melakukan latihan gerak aktif dan pasif dapat memberikan keuntungan yang berbeda. Latihan aktif dapat membantu mempertahankan fleksibilitas sendi dan kekuatan otot. Sebaliknya, gerakan pasif, yaitu menggerakkan sendi seseorang melalui gerakannya oleh orang lain, hanya mempertahankan fleksibilitas serta mampu memaksimalkan fungsi aktivitas kehidupan sehari-hari dengan meningkatkan kemampuan bergerak, mengurangi atau menghambat nyeri dan mencegah bertambah buruknya sistem neuromuskular (Lestari et al., 2017). 
Prinsip Joint protection technique (JPT) yang dapat dilakukan oleh ibu rumah tangga dalam mengaplikasikan pada aktivitas rumah tangga sangat beragam. Aktivitas yang dilakukan antara lain menyapu, mencuci, menyetrika, memasak, menyapu dan belanja. Dalam penerapan prinsip Joint protection technique (JPT) dalam aktivitas kerumahtanggan sangat beragam mulai dari aktivitas menyapu dengan menambah gagang dan menambahkan kain pada gagang sapu (Reduction of effort energy conservation \& work simplification) guna mempernyaman pada saat menggenggam dan menjaga badan tidak terlalu membungkuk. Aktivitas mencuci dengan merubah posisi dengan tidak membungkuk terus menerus ketika mengucek/menyikat pakaian (Avoidance of staying in one positions) mencuci dengan menambahkan kursi duduk dengan sesuai postur tubuh dan mencuci dengan mengganti mengucek dengan menginjak pakaian.

Pada aktivitas menyetrika Menghindari penggunaan tangan yang terasa nyeri/sakit (Avoidance of positions of deformity) dengan mengganti tangan yang sakit ke tangan yang lebih sehat, serta mengganti dengan berat yang lebih ringan. Dalam aktivitas memasak dengan mengistirahatkan tangan/berpindah tangan apabila sudah terasa nyeri ketika memasak (Respect for pain and rest and work balance) dengan menghaluskan bumbu dengan penggunaan blender dan menyiapkan bahan sedekat mungkin dengan jangkauan. Terakhir dalam aktivitas berbelanja dengan menggunakan sendi yang lebih kuat/sehat saat hendak membawa barang belanjaan (Use of stronger/large joint change positions that do not tend to be stressful to involved joint) dengan mengganti kantong plastik yang semula mempergunakan pola hook diganti memakai tas belanja yang dibawa menggunakan bagian forearm (Radius Ulna).

Dari kelima aktivitas tersebut Ibu rumah tangga dapat menerapkan pada aktivitas yang lain. Joint protection technique (JPT) dapat dijadikan strategi koping aktif untuk meningkatkan tugas sehari-hari dan kinerja peran dengan mengubah metode kerja dan menggunakan alat bantu (Niedermann et al, 2011). Dengan dilakukannya prinsip prinsip dengan mulai mengubah positioning aktivitas, merancang aktivitas, dan lainnya dapat mengurangi rasa nyeri yang berlebihan dan mencegah timbulnya nyeri. Teknikteknik pada Joint protection technique (JPT) ini dimaksudkan untuk membantu mengelola peradangan, menghindari rasa sakit, mengurangi kelelahan, dan meningkatkan kebugaran fisik (Setyawati, 2010).

Intervensi yang dilakukan termasuk dalam pendekatan non farmakologi. Dengan adanya intervensi menggunakan Joint Protection Technique (JPT) yang dilakukan selama 1 minggu, terdapat beberapa aspek positif yang bisa diambil oleh ibu rumah tangga. Aspek positif yang terutama yang dialami ibu rumah tangga adalah perubahan nyeri yang bisa dikurangi tanpa dengan penggunaan obat. Perubahan nyeri yang bisa dikurangi dengan menerapkan prinsip - prinsip dari pemberian intervensi Joint Protection Technique (JPT). Mulai dengan perubahan pola aktivitas dengan awal yang tidak pernah dilakukan dengan harus membiasakan pola aktivitas yang diubah. Untuk meringankan dalam aktivitas fisik dan kerja otot yang berkurang dapat menurunkan nyeri yang dirasakan dengan gerakan yang fleksibel/minimalis. Beban aktivitas fisik yang berat dan posisi yang salah merupakan faktor resiko terjadinya nyeri (Ulfah, et al.,2014)

\section{KESIMPULAN DAN SARAN}

Kegiatan penyuluhan kesehatan berupa penerapan JPT dalam aktivitas yang dilakukan ibu rumah tangga di RW 8 Dusun Kebakkalang Desa Kemiri Kecamatan 
Kebakkramat Kabupaten Karanganyar efektif memberikan manfaat pengetahuan dan perubahan perilaku peserta. Peserta yang telah menerapkan JPT dalam aktivitas kerumahtangaan yang dilakukan berdampak besar pada aspek fisik dan psikologis. Pada aspek fisik, peserta merasa ringan saat beraktivitas, tidak mudah lelah dan daya tahan melaksanakan aktivitas tinggi. Dari aspek psikologis paserta merasa lebih bugar dalam beraktivitas. Dari pelaksanaan penyuluhan juga terlihat kesadaran peserta dalam menerapkan protokol kesehatan saat berada di luar lingkungan rumah.

Kegiatan penyuluhan atau pengabdian masyarakat ini perlu mengadakan pertemuan rutin atau penyuluhan via daring melalui grup WA. Ditambahakan dengan pelaksanaan senam untuk mengatasi keluhan muskuloskletal.

\section{UCAPAN TERIMA KASIH}

Terima kasih kepada ibu rumah tangga warga RW 8 Dusun Kebakkalang Desa Kemiri atas partisipasi aktif dalam mengikuti kegiatan pengabdian masyarakat berupa penyuluhan tentang penerapan JPT dalam aktivitas kehidupan sehari-hari. Serta pihakpihak yang telah membantu terselenggaranaya kegiatan ini.

\section{DAFTAR RUJUKAN}

Bobos, P., MacDermid, J., Ziebart, C., Boutsikari, E., Lalone, E., Ferreira, L., \& Grewal, R. (2021). Barriers, facilitators, preferences and expectations of joint protection programmes for patients with hand arthritis: A cross-sectional survey. BMJ Open, 11(1), 1-7. https://doi.org/10.1136/bmjopen-2020-041935

Delgado, D. A., Lambert, B. S., Boutris, N., McCulloch, P. C., Robbins, A. B., Moreno, M. R., \& Harris, J. D. (2018). Validation of Digital Visual Analog Scale Pain Scoring With a Traditional Paper-based Visual Analog Scale in Adults. JAAOS: Global Research and Reviews, 2(3), e088. https://doi.org/10.5435/jaaosglobal-d17-00088

Frost, B. A., Camarero-Espinosa, S., \& Johan Foster, E. (2019). Materials for the spine: Anatomy, problems, and solutions. Materials, 12(2), 1-41. https://doi.org/10.3390/ma12020253

Hammond, A. (2015). Joint Protection: Enabling Change in Musculoskeletal Conditions. In International Handbook of Occupational Therapy Interventions (pp. 607-618). Springer.

Izzeddin Sarsak, H. (2018). Review of effects of joint protection education program for patients with rheumatoid arthritis. MOJ Orthopedics \& Rheumatology, 10(4). https://doi.org/10.15406/mojor.2018.10.00439

Khusna, A. (2017). Pemenuhan kebutuhan body alignment dan body mekanik. Konsep dasar

keperawatan. https://www.academia.edu/41147091/PEMENUHAN_KEBUTUHAN_B ODY_ALIGNMENT_DAN_BODY_MEKANIK

Lestari, R. I., Fauzi, A., Dewi, R., \& Sari, P. (2017). Pengaruh Microwave Diathermy dan Latihan Rentang Gerak Sendi pada Osteoarthritis Lutut di Bandar Lampung 
The Influence of Microwave Diathermy and Range of motion exercise on Knee Osteoarthrits in Bandar Lampung. Kesehatan Dan Agromedicine, 4, 269-274.

Makkiyah, F. A., \& Setyaningsih, Y. (2020). Penyuluhan Osteoarthritis Lutut Pada Ibu Rumah Tangga Di Desa Sirnagalih Jonggol Jawa Barat. Ikra-Ith Abdimas, 3(3), 183-188. https://journals.upi-yai.ac.id/index.php/IKRAITHABDIMAS/article/download/780/586

Noor, M. (2011). pemberdayaan Masyarakat. CIVIS, I(2). https://doi.org/https://doi.org/10.26877/civis.v1i2/Juli.591

Okulicz-Kozaryn, A., \& da Rocha Valente, R. (2018). Life Satisfaction of Career Women and Housewives. Applied Research in Quality of Life, 13(3), 603-632. https://doi.org/10.1007/s11482-017-9547-2

Putri, K. A. K., \& Sudhana, H. (2013). Perbedaan Tingkat Stres Pada Ibu Rumah Tangga yang Menggunakan dan Tidak Menggunakan Pembantu Rumah Tangga. Jurnal Psikologi Udayana, 1(1), 94-105. https://doi.org/10.24843/jpu.2013.v01.i01.p10

Rasdiyanah, R., Wiarsih, W., \& Sukihananto, S. (2020). Health Education Using Booklet and Diary Media on the Self-Efficacy of Housewives with Hypertension. Jurnal Pendidikan Keperawatan Indonesia, 6(1). https://doi.org/10.17509/jpki.v6i1.23205

Setyawati, L. (2010). Selintas tentang kelelahan kerja. Amara Book.

Siregar Cholina Trisa. (2020). Pendidikan Kesehatan Pada Ibu Rumah Tangga Dalam Mencegah TALENTA Conference Series Pendidikan Kesehatan Pada Ibu Rumah Tangga Dalam Mencegah. Talenta Conference Series: Local Wisdom, Social, and Arts, 4(2). https://doi.org/10.32734/lwsa.v4i1.1168

Ulfah, N., Harwanti, S., \& Nurcahyo, P. J. (2014). Sikap Kerja dan Risiko Musculoskeletal Disorders pada Pekerja Laundry. Kesmas: National Public Health Journal, 330. https://doi.org/10.21109/kesmas.v0i0.371 